11

\title{
ON THE IMPLEMENTATION OF AN INFORMATION SYSTEM IN THE MOZAMBICAN CONTEXT
}

The EDM case

Esselina Macome

Faculty of Science, Department of Mathematics and Informatics, Eduardo Mondlane University, Maputo, Mozambique

\begin{abstract}
Information systems are widely acknowledged to be of central importance in contemporary organizations. The transfer of information systems designed for other places that are different from the implementation context, has been part of the global-local debate. In this paper it is argued that the local context should be considered in the implementation of such IS and that local stakeholders should be involved in the entire process. This paper attempts to explore the issue of global-local interaction, and we will use an example of an invoice information system, called Galatee, designed by an international team and implemented in the Mozambican Electricity Company (EDM). Some implications will be drawn for the conference theme on IS perspectives and challenges in the context of globalisation.
\end{abstract}

Keywords: Information System, technology transfer, adoption and use of ICT, actor network theory (ANT), translation, Galatee.

\section{INTRODUCTION}

The implementation process of ICT-based initiatives and the adoption of new management techniques provide organizations in developing countries with the prospect of actively participating in globalization processes which could contribute to national development efforts (Bada, 2000; Avgerou, 2001). In Mozambique many organisations are in the process of implementing different ICT-related projects in order to improve their efficiency. A systematic study on how a specific ICT-related initiative was 
implemented might help to guide future efforts in the country. It is from this perspective that a research study was conducted to address the question: How does a specific ICT-related initiative become institutionalised? To respond to this question a case study was undertaken describing the analysis of an IS adoption in the Electricity Company in Mozambique (EDM). The information system described here relates to the invoicing of electricity in Mozambique, and is called Galatee meaning the 'God of Water'. Galatee is being implemented in five EDM operational areas, namely Maputo City (south), Beira, Chimoio, (centre) Nampula and Nacala in the northern part of Mozambique. A French company called SAUR was contracted by EDM to design and implement this system.

This research is concerned with the process of introducing an innovation that is typically designed in the developed world and introduced to developing countries like Mozambique through a 'technology transfer' process. This process involves not only the transfer of technology but also various organizational and management practices that are often found to contribute to the tensions within the socio-organizational contexts of developing countries (Avgerou, 1996; 2001; Bada, 2000). The potential value and effectiveness of the transfer process is dependent on the local socio-organizational conditions and the ability of the organization to adapt the ICTs to address local priorities (Odedra, 1991; Avgerou and Walsham, 2000).

An approach to studying the process of technology transfer is provided by Rogers' (1995) theory of diffusion of innovations. Diffusion theory researchers have tried to understand the factors that influence ICT/IS innovation adoption decisions (Attewell, 1992; Fuller and Swanson, 1992; Cool et al., 1997), typically at the organizational and intra-organizational level, rather than with an inter-organizational focus (Prescott and Conger, 1995). Another assumption of the traditional diffusion theory perspective has been the homogeneity of the institutional environment across the adopting units, which tends to obscure variations across the units arising from geographic distance from the source of the innovation, local norms and regulations, and the availability or unavailability of factors to support the diffusion system. It has now been well established by IS researchers that contextual factors play an important role in influencing the ability of an organisation to adopt and effectively apply technological innovations (Williams and Edge, 1996; Du Plooy, 1998; Allen, 2000; Walsham, 2001). This view of diffusion theory is especially problematic in the current period of globalisation that is characterised by processes of rapid technological change. 
In this paper, we attempt to address these limitations, drawing upon an alternative theoretical approach that is provided by Actor-Network Theory (ANT) (Vidgen and McMaster, 1996; McMaster et al., 1997; Büscher and Mogensen, 1997; Knights and Noble, 1997; McMaster et al., 1998). The topic of this paper might be considered as contributing to the debate on IS perspectives and challenges in the context of globalisation.

This paper is divided into six main sections. It starts with an introduction in which the research topic is outlined and the importance of the theme of the research is highlighted. The second section describes the research problem and the main objectives of the study. The next section describes the process of how the study was conducted and also presents the setting for the case study. The fourth section starts by describing the case study of the Galatee implementation and continues with the analysis of the case by using the translation phases from the ANT perspective. The findings of the case study based on the ANT perspective are discussed in Section 5. The final section sums up the paper by presenting the conclusion.

\section{RESEARCH PROBLEM AND OBJECTIVES}

Recent advances in ICTs are becoming central to the process of socioeconomic change and development in different contexts, especially that of developing countries (Avgerou, 2001; Avgerou and Walsham, 2000; Walsham, 2001). While different organizations in Mozambique are in the process of implementing different ICT-related projects in order to improve their efficiency, little is known about their impact and the successes that are achieved on the ground. There is currently a dearth of studies that analyze such organizational experiences with new ICTs and associated management techniques, or deal with how these lead to practical improvements in organizational functioning. A systematic analysis of these experiences can help to guide future efforts in the country, and this research seeks to contribute to this body of knowledge.

The main aim of this research study is to analyze how an information system is implemented within a Mozambican organization. To this end an ANT perspective will guide the analysis. 


\section{RESEARCH SETTING, DESIGN AND METHODS}

The main objective of this section is to describe how the research was conducted. The context within which this research took place will also be presented.

The research study was conducted in Mozambique, a developing country in Southern Africa. This country belongs to what are considered the poor countries of the world. Its Human Development Index was calculated at approximately 0,341 and its Technological Achievement Index as 0,066 . The estimated population of this country is about 17.242.240 inhabitants.

In order to study the process of adoption and use of an ICT-related initiative, a case study of the implementation of an invoice information system at the national electricity company was conducted.

The historical context of EDM, the Mozambican electricity company, falls into two main periods, from its creation/inception in 1977 to 1995 as a parastatal company and subsequent to 1995 , as a public enterprise. EDM is a public company and deals essentially with the production and distribution of electrical power to the whole country. It was formed as a parastatal company that was known as EDM_E.E., for the purpose of integrating all the electrical power generation centres that existed in the country, just after independence in 1975. This was expected to make a major contribution towards satisfying the basic needs of the country in terms of electricity, particularly in relation to the development of agriculture, industry, services and the public sector.

With the liberalisation of the economy, in 1995 EDM was transformed into a public company, its mission being to improve the quality of customer service, maximise revenues, introduce new management practices, and promote the autonomy and decentralisation of regional and operational offices. This company has about 2.860 employees and approximately 186.208 customers (EDM, 2000a).

The research approach selected was that of a case study based on the interpretive perspective in order to enable us to increase our understanding of the critical social and organizational issues relating to the adaptation and adoption of ICT/IS in organizations. According to Walsham (1993) the purpose of the interpretive approach in information systems (IS) is to produce an understanding of the context of IS and the process whereby IS influences and is influenced by the context. Interpretive approaches give the researcher greater scope to address issues of influence and impact, and to ask questions such as 'why' and 'how' particular technological trajectories are created (Orlikowski and Baroudi, 1991). 
The fieldwork for this study took place in Mozambique where the EDM is situated. This fieldwork began in May 2000, six months after the Galatee implementation, and lasted for eight months. The historical reconstruction of the story of Galatee, its implementation and use was possible through interviews with key people involved in the project, system users and the analysis of secondary documents and observations, as well as formal and informal conversations. In general, the interviews provided explanations about the functioning of each operational area, challenges being experienced in the ICT initiation and how these are being addressed. This data-gathering process helped to reconstruct the history of each ICT initiative involved in Galatee.

Thus, the empirical component consisted of approximately 38 individual and group interviews, and one group meeting. Interviews typically lasted about 2 hours. The Galatee system demonstration took about 3 hours and much time was spent on informal discussions with many staff members as well as on making general observations.

\section{RESULTS}

\subsection{The EDM case study - Galatee}

\subsubsection{The Technology Used}

As a way to improve the invoicing system and to increase EDM's income, the previous Ingress invoicing system had been implemented in the early nineties by a private IT company, IC. However, it needed to be improved and extended and made Y2K-compliant. Hence a new information system, Galatee, was implemented at EDM. Galatee was based on Sybase in a Unisys environment.

At the head office, there are two powerful Solaris servers for use and backup systems. Data stored in the servers were also backed up on discs (albeit in the same building as the server). In each operational area there were at least two servers linked to the work stations located in the cashier's and client management's offices. The system was designed in such a way that the cashier can use an electronic pen to enter the invoice details at the moment of payment. 
The Galatee system had previously been used in various countries such as the Ivory Coast, Brazil, France and Poland. There was a need to make certain changes in order to accommodate the local context, for instance the use of the Portuguese language. When the research commenced, the process of adapting changes was still in progress. The development team was based in Abidjan. For the implementation in Mozambique all adaptation occurred at the head office where supercomputer mainframes are centralized and control the network of sales work stations in all five operational areas. They are also connected to the EDM server, accessible via a wireless data communications network.

Galatee was developed as a technical tool that could also manage, control and invoice the customers in order to maximize profits. The Galatee system has the following modules:

- Production of the electricity invoice and handling of its payment

- Management of electricity cut-off for those who are not paying their invoices

- Control of partial payment of invoices

- Client management

- Management of off-line cashier.

\subsubsection{Organizational and Political Conflicts}

The new strategy is that Galatee belongs to the invoicing sector, but its operation and data communication form part of the IT Department's function. Based on this strategy, some technical personnel from the IT Department were transferred to the Commercial Department, so as to work closely with the Galatee system.

Some staff from the operational areas felt that there was not enough involvement of local technical people in some IT-based projects in the company. One of the interviewees expressed the following opinion:

I cannot understand why the Mozambican IT staff are not leading this (Galatee) project. This lack of involvement of local IT staff is creating some problems. For instance, all our problems must be reported to SAUR and we are not sure if the language translation of our concerns is well done or not. [Interview 30, pp. 29-30].

Another difficulty relating to the lack of involvement of indigenous people in this project will have to be faced when the SAUR team is no longer at EDM. Since IT staff were not directly involved in the initial development 
phase of the system, and assuming that the IT Department will be responsible for maintenance of Galatee, there is clearly an urgent need to address the issue of IT Department involvement. This problem of lack of involvement of IT staff in the project had already been identified by EDM, but needs to be readdressed. It is important to bear in mind that the IT Department is an official part of the Galatee project team, but its involvement in the analysis and selection process of the software was minimal due to different organizational issues within EDM.

In anticipation of the problems caused by SAUR withdrawal, EDM has been requesting greater and more formal involvement of IT staff. To support this technology (transfer), a team from the IT Department visited the Ivory Coast in May 2001 in order to make a detailed study of Galatee with the development team.

The organizational climate, particularly in one of the operational areas, became tense and fraught with conflict, with rivalries between divisions, and so the staff became demotivated.

Two categories of training were organized, one for IT personnel at the operational area and the other for the billing staff (cashiers). In general, all participants considered that the training was too short and that it did not help them much. One of the interviewees commented 'For me it was not real training; it was a demonstration of the Galatee' [Interview 35, p.34].

The training sessions for the invoicing staff lasted 3 days, which were spent explaining the new commercial policies and the rationale for the new pricing structures. Staff judged it inadequate since it did not provide enough information on the user-computer interface aspects, and it was therefore seen as merely a system demonstration.

With the new computerized system, EDM also implemented a monitoring system to keep track of the number of transactions, the time taken for each transaction, and the types and amount of invoices dealt with by each cashier. However, the Galatee system did not differentiate between two cashiers working at the same work station at different times. This made it difficult to identify the number of invoices dealt with by each cashier. The first cashier who used the work station was simply considered to have handled all the transactions. The invoicing staff were therefore subjected to a change of computer system and its user interface together with changes in training, role and qualifications, working conditions, handling of performance monitoring and reporting.

There are different opinions regarding the Galatee invoicing system project. During the interviews, different users presented the practical problems that they were currently facing. These problems were similar in all 
operational areas and they were also reported in EDM (2000a). The problems presented can be grouped into different categories such as: (a) technical, (b) organizational and managerial, and (c) people-related.

\subsection{The EDM Case as Viewed Through the ANT Lens: Translation Phases}

This section analyses the case study from the ANT perspective by drawing upon the sociology of translation. The focus is on how the actornetworks grow, change and stabilise during the process of adoption and use of Galatee, examined in particular organizational and societal contexts.

The concept of the sociology of translation is based on Latour's (1991; 1997) alternative to technological determinism, in which things do not happen unless other actors make them happen. This implies that each actor who takes the project further may take it in a different direction than that intended by the previous actor. Latour (ibid.) uses the term 'translation' to describe this effect. Translation operates between actors: an actor gives a definition to another actor, and imputes to him/her/it/them interests, projects, desires, strategies, reflexes and afterthoughts (Callon, 1991).

ANT proposes the concept of 'translation' to replace 'diffusion' and sees innovation spreading as a result of how actors 'translate' the interest of others so that they become aligned with their own interests. ANT does not see technology as an independent artefact that 'diffuses' out from one central point, but views technology as part of a complex heterogeneous network of human actors and non-human artefacts. The effectiveness of the transfer process is then dependent on how these networks are created, stabilised and strengthened over time (Callon, 1986; Callon and Law, 1989; Latour, 1999; 2000). Callon (1986) characterizes four moments of translation:

- Problematisation or how to become an indispensable actor

- 'Interessement' or how the allies are locked into place

- Enrolment

- Mobilisation

These are the translation phases that are going to be followed in the analysis of the EDM case in this paper.

\subsubsection{Problematisation}

Problematisation is the first 'moment' of translation where actors seek to identify and define the obligatory point of passage (OPP) and attempt to impose their definition of the problem on others. Problematisation is an 
indispensable moment as it implies that the problem resolution can only be negotiated through the obligatory point of passage.

Identification of actors/agencies is a way to find out who the actors are and what they are doing. Using Latour's language it was necessary to 'follow them' (Latour, 1987) in their daily interactions with Galatee and others actors in their attempts to enrol them. The initiators of the Galatee system at the EDM are the Commercial and Informatics Departments. The key actors in Galatee at the EDM consist of five main organisational groups: the initiators, the Invoice unit, Cashiers, the Training Unit at the Human Resource Department and the consultant company - SAUR. Other actors included the data items, the technological infrastructure, organizational and management routines and procedures, external influences like the Mozambican ICT policy, French Cashier Agency financing support, management policy and the expectation of the EDM Customers. The characterisations of some of these actors formed part of the description of the case study in the previous section.

Each of the actors has a role to play and an interest in being part of the actor network. The next part shows examples of the role and interests of some actors. The Commercial Department is responsible for all commercial issues involved in managing the sale of electricity; the basic product of $\mathrm{EDM}$, to its customers throughout the country. One of the tasks of the Commercial Department is to collect data about electricity consumption, to produce invoices and collect payments. In addition, this department serves as the interface point between EDM and its clients. The IT Department is responsible for strategic and operational level IS/IT issues. The IT Department was marginally involved in the initial stage of the Galatee project, but subsequently became crucial at the point of conversion of data from the Ingress system to Galatee. The invoice personnel have the task of introducing the raw data (electricity consumption units) into the system for the production of invoices, which are then distributed to the customer's residences. The cashiers use the Galatee system to collect payments from the customers based on the invoice and receive all payments made to the company, for example, payments concerning electricity contracts, overdue payments and others.

The initiators of the Galatee system problematised the initiation of Galatee by pointing out that the Ingress system was not Y2K-compliant and that there was also a need to have a customer-oriented, integrated, computerbased information system. It was argued that Galatee would contribute to the efficiency and extension of control of EDM through improved payment 
collections. These arguments constituted the rationale behind EDM's decision to purchase the Galatee system.

Galatee became an OPP for the various departments, as it was only by using this system that electricity bills could be invoiced, and electricity sold to the public. For instance, the Commercial Department sees Galatee as a way to achieve efficiency in invoicing and client services and hence to achieve the EDM objectives of customer satisfaction and improving collection revenues. The commercial manager from Nampula described their aims:

Since transformation of the EDM into a public enterprise, we are becoming more and more committed to the improvement of quality service to our clients. So if we have an efficient information system, which supports us in this area, we think that we will change the EDM's present situation. This means that we will be able to collect more payments [Extract from the commercial report of the Operational Area Nampula, pp. 3-4].

\subsubsection{Interessement}

At present the system has been partially implemented in all the EDM operational areas. However, there is a need to ensure that all its modules are properly used, and also to interest other user departments in making better use of Galatee.

Being part of the Commercial Department, the Invoice Unit naturally sees the use of Galatee as integral to its functioning, and is therefore interested in increasing Galatee's role.

There is a pervasive and accepted Mozambican cultural principle that dictates that subordinates must obey their managers, making it only a remote possibility that the cashiers (front-end users) might reject this system. The managers will try to ensure that the cashiers accept the system, and the latter will feel obliged to obey the decisions made by their managers. Therefore, there are few grounds for expecting any type of resistance from the personnel when it comes to using the new system. Administrative disciplinary techniques, such as the evaluation, monitoring system and control of transactions made by each cashier, were also introduced to ensure the staff's compliance. This institutionalised discipline of cashiers ensures the Commercial Department's successful interessement.

The process of monitoring and controlling transactions led to the involvement of the Finance and Audit Departments in using Galatee as a 
tool to control the collection of payments from the customers. For example, in Nampula we found the contracts of three cashiers with EDM being cancelled due to irregularities in the payment of electricity invoices (EDM, 2000b).

The IT Department used the opportunity presented by Galatee implementation to convince the EDM top management to upgrade the enterprise-wide ICT infrastructure and to define a new strategic role for ICT in rendering organizational change possible and improving efficiencies.

The managers presented the system to the EDM employees as an opportunity to overcome the $\mathrm{Y} 2 \mathrm{~K}$ problem and as a means of increasing efficiencies.

\subsubsection{Enrolment}

Enrolment requires the initiators to persuade and convince the other actors to join them. The motivation of all actors is of central importance to enrolment, since enrolment has to do with bonding elements together.

The initiators of Galatee decided to acquire an integrated customeroriented, computer-based invoicing information system from the international market based on the argument of lack of adequate in-house IT skills to develop the system and to comply with the conditions of the funding source market. As a result, the $S A U R$ was contracted to undertake the development and implementation of the required system for EDM.

The SAUR experienced many problems during the implementation of the Galatee system, including some that inhibited communication, as well as the fact that not all EDM conditions were included the system. For example, the cashiers could not differentiate between currencies (MZM - Metical or US \$) in the invoices' payments. Presently the customer, depending on his/her contract, can pay the electricity invoice in the national currency or in American dollars. In addition, the Galatee system did not permit the cashiering of the overdue amount, forcing the cashiers to make these transactions manually. This made it difficult to handle all customers using the same procedures.

The IT Department's involvement during the procurement of the system was not a smooth process. Despite this situation, the project manager achieved a high enrolment of IT Department members during the implementation by emphasising their role in the success of implementation of this system after the SAUR finished its work and left.

All initiators continue to be part of the network implementing Galatee, and new actors also joined this network. 


\subsubsection{Mobilization}

The mobilization of actors, according to Callon (1986: p. 216), results in rendering agencies mobile that were static beforehand, in order to traverse the defined OPP. This helps to strengthen the network of alliances and provides stable information systems, and renders possible the linking of agencies that were not linked before. For example, the cashiers who were not linked to the client management personnel earlier on (opening contract, etc.), now became linked. This implies that Galatee could only be stabilized when relations between these actors were established. Since not all modules of Galatee were implemented as yet, further and new relations between actors would need to be built up during the process of adopting and using other Galatee modules.

In summary, the initiators - the Commercial and IT Departments proposed Galatee as the only solution to the $\mathrm{Y} 2 \mathrm{~K}$ problem and to improve invoicing efficiency. The implementation of Galatee helped to build a strong network of alliances between the Invoice Unit personnel, and the Finance and Auditing Departments. It seems that Galatee has become an indispensable resource in the commercial area of EDM, although the network for its implementation is not yet closed. The designers of this system are still in the process of adapting it to the EDM regulations and procedures. The personnel who are directly affected by Galatee are attempting to learn the required skills to use it. However, some personnel have showed dissatisfaction with project management practices, as well as with the level of Galatee adaptation and as regards the responsiveness of the development team in addressing their problems. This was due to the low level of consultation with the users in the adoption and use of Galatee. As a result, the new EDM network was not clearly defined and recognized by all users, thus influencing the level of institutionalization of Galatee within EDM.

\section{DISCUSSION}

The experience of the implementation of Galatee at the EDM suggests a number of insights for both theory and practice related to ICT/IS implementation in organizations. This case illustrates an aspect that has been emphasized by other researchers - the importance of involving users in the process of introducing new ICT initiatives. This brings to the debate the issue of team building for the ICT/Is implementation. In this case, it was 
clear that the level of user involvement was low and this could have contributed to the creation of some of the aforementioned problems.

The analysis of this case study has implications for the transfer of ICT and management techniques in the context of the debate about global-local interaction. The Information system analyzed in this paper was developed in other countries and applied in Mozambique as part of the globalization process. One of the implications is that global-local interaction does not happen in a homogenous context. This implies that the local context must be able to mediate global influences in order to derive benefit from this interaction process. Evidence from the case study also suggests that ICTrelated initiatives implemented in the case as features of the global institutional environment, were adapted in an organizational context. From this point of view, in the implementation of a new ICT-related initiative the social context, and the history and tradition of doing things within the local organizational context must be taken into consideration. Consequently this implies that the organizations need to have skilled human resources with the ability to creatively adapt new technologies and global practices to the local context and also manage the whole process of implementation. This has significant implications for human resource development as well as for education.

From this case study, it is apparent that one of the major challenges of the process of adoption and use of ICT in organizations is related to the transformation of the organization in order to meet customer and competitive demands. This transformation has to be seen as facilitating the capacity to learn to manage ICT-enabled change.

New ways of working necessarily bring about shifts in organizational power, culture, process and structure. This also implies a redistribution and diffusion of learning in the organization caused by a new way of working. This study shows, as other studies have, how difficult it is to manage change. ICT-enabled change adds a new dimension of difficulty; new technologies stimulate unprecedented processes of change throughout the organization, including shifting the location of knowledge levels within the organization.

Another important role is to educate the organization's business units to be directly involved in the process and understand the implications of change before initiatives are implemented. This indicates the need to learn what change management is, and how to control new processes in the context of organizational transformation.

Overall, the above findings reinforce the value of adopting an interpretivist perspective and the use of ANT to focus on meaning and flow with the active actors in the building and stabilizing of a network. 


\section{CONCLUSION}

The story described in the EDM case study in this paper is a story about active builders of socio-technical actor-networks, and how the actor-network grows, changes and stabilizes within the global and local interaction perspective.

The four steps in the translation of the adoption and use of ICT-related initiatives point to different skills that human actors (such as managers, ICT professionals, and users) may develop to enhance their interaction with the non-human actors. Problematisation and interessement demonstrate how important it is for the managers and ICT professionals to develop communication skills, which permit them to convince and persuade other agencies to traverse the OPP. Enrolment depends on the capacity for negotiation of the initiators to convince other actors to enrol in the initiative. This means that the negotiating skills of initiators (managers, ICT professionals) might increase the likelihood of enrolling other agencies. The mobilization phase is concerned with the identification of the spokesmen or representatives integrated in the network.

From this analysis three major issues emerge: (a) the role of actors' involvement and their efforts to introduce and institutionalize a new system such as Galatee; (b) the communication and negotiation skills of the actors to create, translate and stabilize the network of alliances; and (c) the management of the implementation process itself as an organizational change.

Through the description and analysis of this case study, we are attempting to contribute to the global-local debate by arguing that the implementation of the ICT-related initiatives in organizations should take into account the local context as a way to contribute towards the likelihood of the ICT initiative becoming institutionalized.

\section{ACKNOWLEDGEMENTS}

The author would like to thank the representative of the EDM who gave her the opportunity to research a real-world situation. I also thank the IFIP8.2\&9.4 referees for their valuable and constructive comments. My grateful thanks also go to my $\mathrm{PhD}$ supervisor, Professor JD Roode, for his constructive comments during this research work. 


\section{REFERENCES}

Allen, J.P. "Information Systems as Technological Innovation", Information Technology \& People, (13:3), 2000, pp. 210-221.

Attewell, P. "Technology Diffusion and Organisational Learning: The Case of Business Computing", Organisation Science, (3:1), 1992, pp. 1-19.

Avgerou, C. "Transferability of Information Technology and Organisational Practices", in Global Information Technology Socio-Economic Development, edited by M. OdedraStraub, Ivy League, Nashua, New Hampshire, 1996, pp. 106-115.

Avgerou, C. Information Systems the Diversity of Globalisation, UK: Oxford University Press, 2001.

Avgerou, C. and Walsham, G. Editors of Information Technology in Context, Perspectives from Developing Countries, UK: Ashgate, 2000.

Bada, A. B. "Global Practices and Local Interests: Implementing Technological-Based Changes in a Developing Country Context", PhD thesis, Department of Information Systems, LSE, University of London, 2000.

Büscher, M. and Mogensen, P.H. "Mediating Change: Translation and Mediation in the Context of Bricolage", in Facilitating Technology Transfer Through Partnership Learning from Practice and Research edited by T. McMaster, E. Mumford, E; B. Swanson, and D. Wastell, London: Chapman \& Hall, 1997.

Callon, M. "Some Elements of a Sociology of Translation: Domestication of the Scallops and the Fishermen of St Brieuc Bay", in Power, Action and Belief: edited by J. Law, Routledge and Kegan Paul, London and New York, 1986, pp. 196-233.

Callon, M. "Techno-Economic Networks and Irreversibility", in A Sociology of Monsters: Essays on Power, Technology and Domination, edited by John Law, Sociological Review Monograph 38, London, England, 1991, pp. 132-161.

Callon, M. and Law, J. "On the Construction of Socio-technical Networks: Content and Context revisited", Knowledge and Society, (9), 1989, pp. 57-83.

Cool, K.O., Dierickx, I. and Szulanksi, G. "Diffusion of Innovations Within Organisations. Electronic Switching in the Bell System 1971-1982", Organisation Science, (8:5), 1997.

Du Plooy, N. F. "An Analysis of the Human Environment for the Adoption and Use of Information Technology", PhD thesis, University of Pretoria, South Africa, 1998.

Electricidade de Moçambique (EDM). Relatório Interno: Problemas do Galatee, EDM, Maputo, Mocambique, 2000a.

Electricidade de Moçambique (EDM). Despacho de Cancelamento de Contratos de dois Funcionarios - Caixas, Área Operacional de Nampula, Nampula, Mocambique, 2000b.

Fuller, M. K. and Swanson, E. B. "Information Centers as Organisational Innovation: Exploring the Correlates of Implementation Success", Journal of Management Information Systems, (9:1), 1992, pp. 47-67.

Knights, D. and Noble, F. "Networks and Partnerships in the Evolution of Home Banking", in Facilitating Technology Transfer Through Partnership Learning from Practice and Research, edited by T. McMaster, E. Mumford, E.B. Swanson and D. Wastell, London: Chapman \& Hall, 1997.

Latour, B. Science in Action: How to Follow Scientists and Engineers through Society, Cambridge, Massachusetts: Harvard University Press, 1987.

Latour, B. "Technology is Society Made Durable" in A Sociology of Monsters. Essays on Power, Technology and Domination: edited by J. Law, Routledge, London and New York, 1991, pp. 103-131. 
Latour, B. "On Actor-Network Theory: Few Clarifications", Centre for Social Theory and Technology, Keele University, UK, 1997.

Latour, B. "On Recall ANT", in Actor Network Theory: and After, edited by B. Latour, J. Law, and J. Hassard, Oxford: Blackwell, 1999, pp. 15-25.

Latour, B. "When Things Strike Back - A Possible Contribution of Science Studies", British Journal of Sociology, Special Millenium issue, 2000, edited by J. Urry. Available at: http://www.ensmp.fr/ latour/Articles/sciencesstudies.html, (Accessed at 25 June, 2001).

McMaster, T., Vidgen, R. T. and Wastell, D. G. "Technology Transfer: Diffusion or Translation?", in Facilitating Technology Transfer Through Partnership Learning from Practice and Research, edited by T. McMaster, E. Mumford, E.B. Swanson and D. Wastell, London: Chapman \& Hall, 1997.

McMaster, T., Vidgen, R. T. and Wastell, D. G. "Networks of Association and Due Process in IS Development", IFIP WG 8.2 \&8.6 Joint Working Conference on IS: Current and future changes, Helsinki, Finland, December, 10-13/1998.

Odedra, M. "IT Transfer in Developing Countries: The Three Case Studies from Kenya, Zambia and Zimbabwe", Ph.D thesis, LSE, London, 1991.

Orlikowski W. J. and Baroudi, J. J. "Studying Information Technology in Organisations: Research Approaches and Assumptions", Accounting, Management and Information Technologies, (1:1), 1991, pp. 9-42.

Prescott, M. B. and Conger, S. A. "Information Technology Innovations: A Classification by IT Locus of Impact and Research Approach", Data Base Advances, (26:2\&3), 1995, pp. 20-41.

Rogers, E.M. Diffusion of Innovations, Free Press, (4th edition), 1995.

Vidgen, R. T. and McMaster, T. "Black Boxes, Non-human Stakeholders and the Translation of IT through Mediation", in Information Technology and Changes in Organizational Work: 239-249, edited by W.J. Orlikowksi, G. Walsham, M.R. Jones and J.I. DeGross, Proceedings of the IFIP WG8.2 Working Conference, Cambridge University, 7-9 December 1995, London: Chapman and Hall, 1996.

Walsham, G. Interpreting Information Systems in Organisations, New York, USA: John Wiley \& Sons, 1993.

Walsham, G. Making a World of Difference: IT in a Global Context, West Sussex, England: John Willey \& Sons, 2001.

Williams, R. and Edge, D. "The Social Shaping of Technology", in Information and Communication Technologies, edited by $\mathrm{H}$. William and Dutton, England: Oxford University Press, 1996.

\section{About the Author}

Esselina Macome is a lecturer in Information Systems at the Eduardo Mondlane University, Maputo City, Mozambique. She was born in Maputo - Mozambique, and achieved her MSc in Information Systems at the University of London, LSE. She is presently in the process of completing her $\mathrm{PhD}$ at the University of Pretoria, South Africa. Her research interests include organizational and social aspects of ICT/IS. She can be reached by e-mail at macome@nambu.uem.uem or uffo@zebra.uem.mz, or through the Department of Mathematics and Informatics, Faculty of Science, UEM, P.O. Box 257, Maputo, Mozambique, Tel/fax 2581493377. 